\title{
Assessing subsoil void hazards along a road system using H/V measurements, ERTs and IPTs to support local decision makers
}

\author{
Veronica Pazzi ${ }^{1 *}$, Mattia Ceccatelli ${ }^{1}$, Teresa Gracchi ${ }^{1}$, Elena Benedetta Masi ${ }^{1}$, \\ Riccardo Fanti ${ }^{1}$
}

${ }^{1}$ Department of Earth Sciences, University of Firenze, Via G. La Pira 4, 50121 Firenze, Italy

Received July 2017, revision accepted April 2018

\begin{abstract}
Between 2008 and 2014, nine sinkholes occurred in northeastern Elba Island (Tuscany, Italy), an area with mostly flat terrain (called "Il Piano") separating the municipalities of Rio nell'Elba and Rio Marina. The last sinkhole damaged the only road (SP26) between the harbour of Rio Marina and the northwestern part of the island. A bypass was immediately built, but the SP26 remains closed. Considering that sinkholes could be densely clustered in sinkhole prone areas, their detection and forecasting are key aspects of local administrative policies. In this paper, we present the results of an integrated geophysical survey aimed at (i) characterizing the geology of the area surrounding the SP26, and (ii) assessing the subsoil void hazard around the road system to support the decision to replace or restore the SP26. Therefore, for the purposes of this research, 120 singlestation seismic noise measurements were taken following the horizontal-to-vertical spectral ratio $(\mathrm{H} / \mathrm{V})$ or Nakamura technique, while eight 2D electrical resistivity tomography (ERT) and 17 3D-ERT/induced polarisation measurements were also carried out in the study area. The H/V method allowed the estimation of the mean thickness of the alluvium, whereas the 2D/3D-ERTs and IPTs permitted the characterisation of the electrical behaviours of the materials and the localisation of the lenticular sand and gravel bodies within a sandy silt layer. The large amount of collected data made the zonation of the subsoil void hazards possible.
\end{abstract}

Key words: 3D electrical tomography, H/V method, Induced polarisation, Integrated geophysical approach, Sinkhole susceptibility assessment.

\section{INTRODUCTION}

The term "sinkhole" is often used to define surface depressions, cavities, and dolines, regardless of the geological scenario, the shapes, the formation processes, and the triggering factors (natural, anthropic, or mixed) of these features (Caramanna, Ciotoli and Nisio 2008; Parise and Lollino 2011; Cardarelli et al. 2014; Kaufmann 2014). Thus, according to the scientific literature and the USGS (2016), a huge variety of sinkhole classifications exists, even though initially (Fairbridge 1968) the term "sinkhole" was employed to indicate a subcircular surface depression caused by a small subterranean karst cavity collapse.

The interaction between human activities and geology is one of the causes of the progressive increase in the sinkhole hazards and vulnerabilities of several sites (Lazzari, Loperte and Perrone

"veronica.pazzi@unifi.it
2010). Because of their formation processes, many authors have observed that sinkholes are generally densely clustered in sinkhole prone areas. This clustering is seen in the case of Hutchinson in Kansas (Ivanov et al. 2013) or Florida (Dobecki 2010; Krawczyk et al. 2012) where, in 2009, approximately 200 sinkhole alarms occurred per month. Intrieri et al. (2015) showed two examples in Italy where 35 and 58 sinkholes could be mapped within $7 \mathrm{~km}^{2}$ and $6 \mathrm{~km}^{2}$, respectively.

Subsoil voids exposed to groundwater flow may become enlarged and may migrate toward the surface (Fenning, McCann and Veness 1994). Since caves in karst environments or anthropogenic cavities (e.g., tunnels, buried passage, and catacombs) are prone to sudden collapses, if the collapses occur in densely inhabited areas, they are a serious natural hazard to human safety and infrastructures (Cardarelli et al. 2010; Krawczyk et al. 2012). Sinkholes are one of the natural hazards that can cause direct losses during and immediately after the events, as well as 
interrupting businesses, transportation networks, and communications, thereby affecting also areas far away from the sinkhole. These events can also produce intangible losses, like the cost of relocating urban areas (Intrieri et al. 2015).

According to Lazzari et al. (2010) and Kaufmann (2014), the delimiting of subsoil-void-prone areas, detecting the presence of natural or anthropic caves, assessing their time evolution, and setting up early warning systems are key aspects in sinkhole risk assessment and mitigation, especially in urban areas. No specifically developed techniques are employed in sinkhole detection, forecasting, and monitoring aside from the traditional direct and indirect ones. Usually, geotechnical and geophysical surveys carry out the mapping of subsoil void geohazards in built-up areas, but these surveys are almost always conducted in and around structures that are above or under the ground (Dobecki 2010). According to many authors (Zhou, Beck and Adams 2002; Krawczyk et al. 2012; Ivanov et al. 2013; Samyn et al. 2014; Lee et al. 2016), in urban areas, invasive direct methods (e.g., blind drillings and electric CPT) may be too expensive in terms of their cost and time and may exacerbate sinkhole development. Also, traditional geophysical measurements (i.e., electric resistivity, active and passive seismics, electromagnetics) may not be effective because of (i) severe logistic limitations, (ii) high background noise caused by human activities, and (iii) highly disturbed ground (Cardarelli et al. 2010; Dobecki 2010; Krawczyk et al. 2012).

The problem related to the application of geophysical techniques in built-up environments has been known since the early 90s, when Henderson (1992) stated that special approaches and new methods of interpreting results were required since surveys were more often carried out in urban environments. At the beginning of the century, Dabas, Camerlynck and Camps (2000) noted that the need for geophysical expertise in developed areas was growing as a consequence of new infrastructures (parking, roads, and buildings), development, and the increasing social consciousness for the preservation of cultural heritage. When a geophysical survey is carried out in an urban environment, the background noise becomes a major hindrance, and any interpretation requires innovative thinking (Dobecki 2010; Miller 2010). The challenge is, therefore, to adapt traditional techniques to increase the signal and isolate the signal from the noise while still taking advantage of the noise and transforming it into useful signal.

Over the years, different geophysical techniques have been employed to map natural cavities. The effectiveness of a geophysical method varies with the characteristics of the survey, and only their integration allows for a better data interpretation. Especially in an urban environment, selecting an appropriate geophysical method calls for taking into consideration the trade-off between their advantages, their intrinsic limitations and ambiguities, and their cost-to-time ratio (Piro, Tsourlos and Tsokas 2001; Dobecki and Upchurch 2006; Pueyo Anchuela et al. 2013; Cardarelli et al. 2014; Pazzi et al. 2016c). These methods are known to detect variations of the ground's physical properties (e.g., electrical resistivity (ER), chargeability, seismic wave velocities, magnetic susceptibility, and density). Underground voids can be filled with water, air, or collapsed/unconsolidated material, and therefore, these features generate distinct geophysical contrasts detectable at the surface (Bishop et al. 1997; Ivanov et al. 2013; Kaufmann 2014; Samyn et al. 2014).

Martinez-Moreno et al. (2013) summarised the main studies carried out from 1975 to 2011 to detect caves by means of geophysical surveys and indicated their approximate penetration depths (ranging from 4 up to $80 \mathrm{~m}$ ). Gravity/microgravity methods have been used since the 1960s to detect superficial caves (Chico 1964) and are currently still employed despite not being cost effective as a result of the huge amount of field work and post-processing corrections required (Butler 1984; Paine et al. 2012). Since the 1970s, ER and induced polarisation (IP) methods have also been used (Smith and Randazzo 1975; Sogage, Vichabian and Dale Morgan 1999; Milsom and Eriksen 2011). Moreover, in the early ' 90 s, these techniques started to employ tomographic arrays and are currently the key techniques for detecting near-surface anomalies from both geological and human origins (Smith 1986; Loke and Barker 1996; Zhou et al. 2002; Giampaolo et al. 2016; Pazzi et al. 2016c). The spatial distribution of the subsoil ER and chargeability can provide useful information for characterizing the heterogeneities of sediments as well as for reconstructing aquifers or aquiclude geometries (Giampaolo et al. 2016 and references therein). Nevertheless, electrical resistivity tomography (ERT) often fails in urban and industrialised areas where strong electromagnetic noise or ferroconcrete constructions interfere (Krawczyk et al. 2012 and references therein). The combination of microgravity and ERT/IP is therefore a powerful tool for the detection of underground cavities as well as for distinguishing whether an underground cavity is empty or filled (McDonald and Davies 2003). The self-potential (SP) method is also applied in sinkhole detection and, like the ERT, is reasonably user friendly as well as being generally time and cost effective (Jardani, Dupont and Revil 2006; Giampaolo et al. 2016).

Ground-penetrating radar (GPR) is currently one of the most common and widely used geophysical survey methods, even though its penetration depth is limited to a few metres and the signal can be scattered in heterogeneous conditions, such as rocky soils or alluvial deposits with high clay contents (Pueyo Anchuela et al. 2009; Lazzari et al. 2010; Lee et al. 2016). Finally, active and passive seismic methods are often employed to detect sinkholes (Ezersky 2008; Sgarlato, Lombardo and Rigano 2011; Krawczyk et al. 2012 and references within; Ezersky et al. 2013; Samyn et al. 2014). Ivanov et al. (2013) states that roof rock failure can be approximately predicted from the shear modulus since the probability of a void's roof failure increases as the measured shear-wave velocity increases in the roof rock. Unfortunately, if caves are located at depth, they exemplify a situation where non-invasive determination of 
shear-wave velocities in an urban setting would be extremely challenging when using any active seismic method. Recent studies have shown how the analysis of surface waves is also useful in urban environments (Martì et al. 2008; Ivanov et al. 2013; Krawczyk, Polom and Beilecke, 2013).

In this paper, the results of an integrated geophysical survey carried out at "Il Piano" (Elba Island, Italy) to assess the subsoil void hazards along the road system are presented. The study area was affected by at least nine sinkholes between 2008 and 2014 (Intrieri et al. 2015), and the local administrations would like to know whether to replace or restore the SP26, damaged by the last one. Looking at the geological map of the area, the road system was clearly constructed on alluvial deposits and runs parallel to the drainage networks. To obtain a suitable geological characterisation of the area, 2D and 3D ERT, chargeability measurements (IPT), and single-station seismic noise measures taken according to the horizontal-to-vertical spectral ratio (H/V) technique (Nakamura 1989; Lermo and Chavez-Garcia 1994; Fäh, Kind and Giardini 2001; Lotti et al. 2015) were carried out. The last method is based on microtremors characterised by low levels of energy and low amplitudes. It has proven to be one of the most appropriate methods to estimate (i) the resonance frequencies of soft deposits (Del Gaudio, Muscillo and Wasowski 2014; Larose et al. 2015, Lotti et al. 2017; Pazzi et al. 2017b), (ii) the interactions between soil and buildings (Herak 2008; Pazzi et al. 2016a, b), and (iii) the presence of underground voids, both natural or anthropic (Castellaro and Mulargia 2009a). Cavities do cause a shear velocity inversion that is clearly distinguishable in the $\mathrm{H} / \mathrm{V}$ curve of values $<1$.

Because of the logistic restrictions to acquisition (i.e., the boundaries of the residential lot), even though the areas around the road system are not as heavily developed, the field survey did encounter some problems. In the following, we discuss how the 3D acquisition allows us to overcome these problems. Finally, the integrated approach to reconstruct the shallow paleochannel distribution is presented. According to some authors (Reitz and Eskridge 1977; Newton and Mark Tanner 1987), paleochannels and, therefore, subsuperficial water circulation in the aquifer hosted in the upper layer are responsible of the surface instability phenomena. Taking into consideration the results of the hydrogeological survey carried out in the study area, together with the historical maps and aerial photographs studies (Intrieri et al. 2018), the main hazards of the study area is related to an ineffective maintenance of the superficial and shallow drainage networks, rather than the presence of caves as supposed in the past (Intrieri et al. 2015).

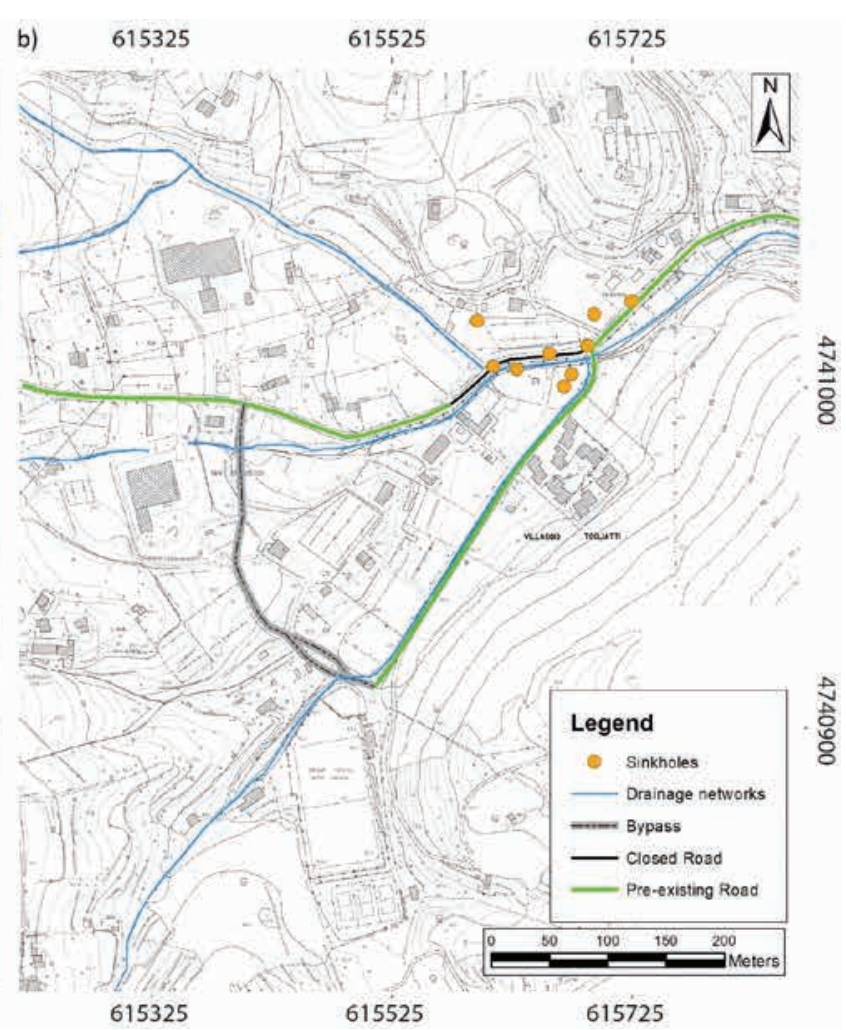

a)

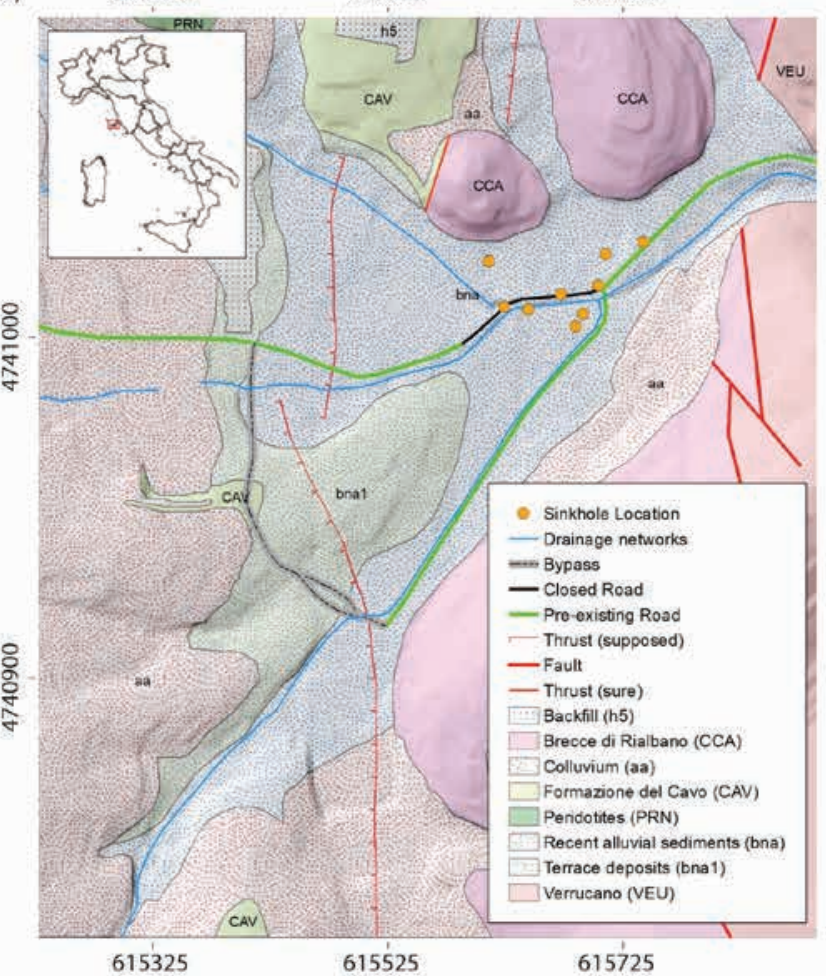

Figure 1 a) Zoomed view of the detailed geologic map (modified after Intrieri et al. 2015) defined based on the ancillary 1:25000 map by ISPRA (2015) and further in situ investigations. In the upper left corner, the study area is shown (red box) with respect to the Italy b) Zoomed view of the regional technical map of the study area. In a) and b), the black line is the provincial road "SP26", which was closed to traffic after the 2013 sinkhole; the green line shows the pre-existing road system that is still open to traffic; the grey line shows the new bypass; and the blue lines show the drainage network. Moreover, the orange dots are the sinkholes that occurred between 2008 and 2014. 


\section{STUDY AREA}

Elba Island is located in the Northern Tyrrhenian Sea between Tuscany (Northern Apennines Chain) and Corsica (Alpine Corsica structural pile) and is considered as the innermost outcrop of the Northern Apennines Chain. From a geological point of view, the western part of the island is characterised by a Late Miocene monzogranitic plutonic masses (Monte Capanne), whereas the eastern part comprises a tectonic pile of sedimentary formations affected by the intrusion of the Messinian-Pliocene magmatic bodies (Ferrara and Tonarini 1985; Rocchi et al. 2002; Mainieri et al. 2003). A model dividing the nappe pile into five complexes was proposed by Trevisan (1950), which was then successively slightly modified by Barberi et al. (1967, 1969). According to Trevisan's model, the Tuscany units (Complexes I, I,I and III) are overlapped by the Ligurian ones (Complexes IV and V): the lower three have continental features, whereas the upper two are oceanic. More recently, Bortolotti et al. (2001) proposed an updated model of the structure of Elba Island based on the presence of the nine main tectonic units belonging to the Piedmontese, Ligurian, and Tuscan domains.

The study area (Figure 1) in the northeastern part of the island is part of the municipalities of Rio nell'Elba and Rio Marina. Herein, the bedrock comprises Formazione del Cavo and Brecce di Rialbano formations, with the first tectonically overlying the second due to a N-S-oriented, W-dipping fault. The Formazione del Cavo is a metamorphosed siltstone with polyschistose calcschists and varicoloured slates, whereas the Brecce di Rialbano formation, already known as Calcare Cavernoso, is a brecciated dolomitic limestone (Bortolotti et al. 2001; Intrieri et al. 2015). Over the bedrock, a coverage of alluvial and erosional deposits is present, with a medium thickness of 20-30 m that includes lenticular gravel and sand bodies within a sandy silt matrix.

The geomorphology of the area (Figure 1a) is a result of the alternating depositional and erosional events that occurred as a consequence of the sea level fluctuations during the late Pleistocene and Holocene periods. Because of this phenomenon, the area is characterised by a sequence of continental deposits (i.e., of lacustrine, fluvial, and hillslope deposits). The aforementioned formations are considerably different from a hydrogeological point of view. The Brecce di Rialbano formation shows high permeability values, mainly due to the fractures caused by tectonic and karst phenomena, whereas the Formazione del Cavo is characterised by a very low hydraulic conductivity. In this context, two different aquifers can be identified. The shallowest one can be recognised in the Quaternary deposits, whereas the deepest and most significant one is hosted in the karst fractures that characterise the limestone formations. Both have been deeply exploited for industrial, agricultural, and drinking purposes (Intrieri et al. 2015).

Between 2008 and 2014, several sinkholes of different diameters $($ min diameter $=1 \mathrm{~m}$, $\max$ diameter $=10 \mathrm{~m})$ occurred in the
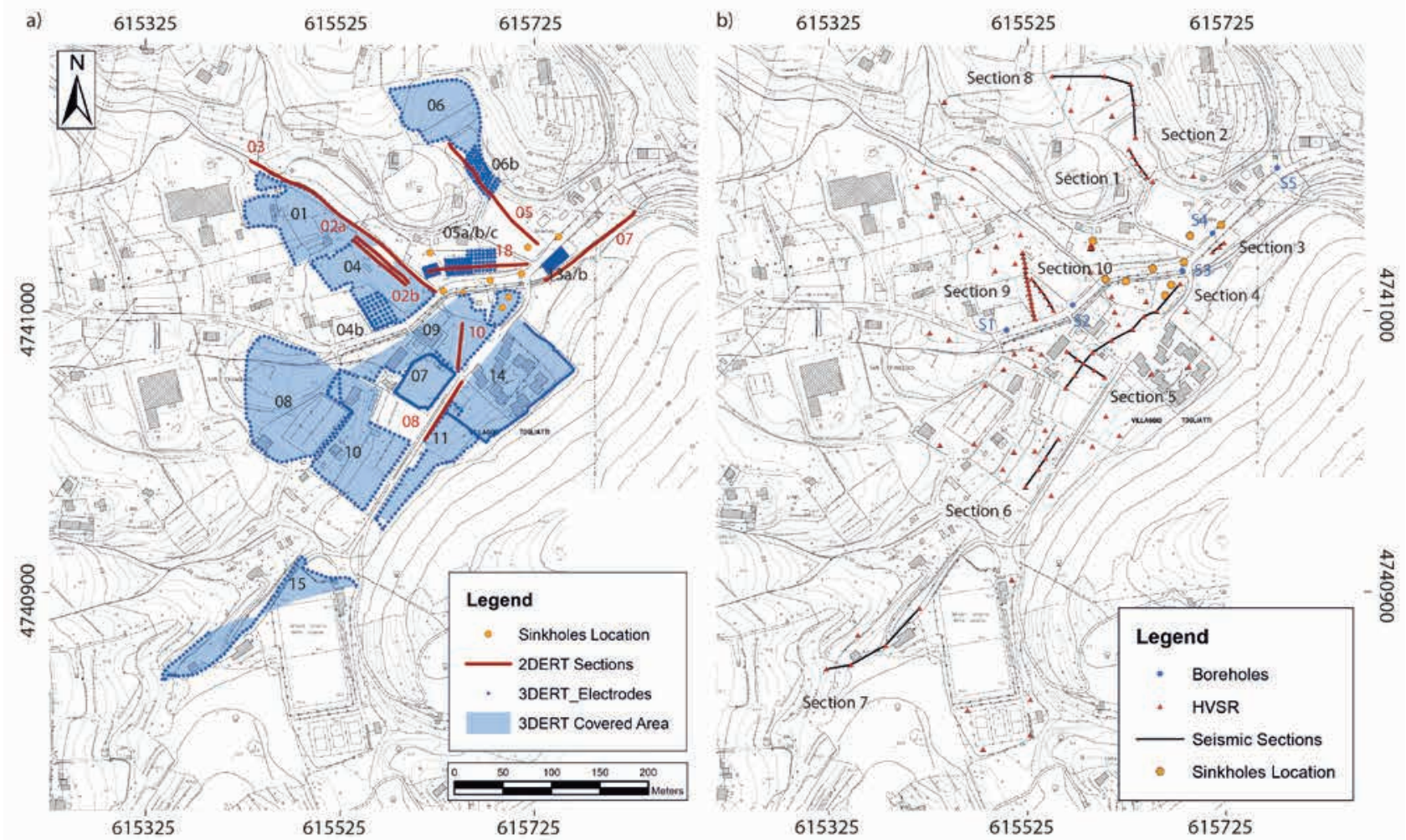

Figure 2 a) Locations of 2D-ERT (red lines) and 3D-ERT surveys (the blue dots mark the locations of the electrodes, while the light blue areas delimit the extensions of effectively investigated areas); b) H/V single-station seismic noise measurements (red triangles) and the 10 selected alignments. The blue dots identify the boreholes numbered from S1 to S5 from west to east. 
area (Figure 1(a,b)). Intrieri et al. (2015) proposed a model that related the instability to the sediment erosion from the alluvium caused by the downward water circulation between the aquifers. In this area, the road system included the SP26 and a secondary road. The latter borders the Villaggio Togliatti area, connecting the city centre with the sports field. The SP26 is the only connection between the harbour of Rio Marina, used both for tourism and commercial purposes, and the northwestern part of the island. The last sinkhole that occurred in 2014 involved both lanes of the SP26 (for a total diameter on the order of metres). The SP26 road was closed from $21+850$ to $21+980 \mathrm{~km}$ (shown in black in Figure 1(a,b)), and a temporary bypass (in grey in Figure $1(a, b)$ ) connecting the secondary road to the SP26 was immediately built. To date, the SP26 remains closed.

\section{METHODOLOGY}

\section{Design of the ERT, IPT and H/V spectral ratio layouts}

As mentioned in the Introduction, the goals of the study were to obtain a suitable geological characterisation of the area and to detect the possible cavities/subsoil voids around the road system that could be enlarged and migrated to the surface. The design phase of the measurements had to account for the peculiarities of the study area. First, the 2D-ERTs parallel and orthogonal to the two main roads were designed. Because of logistical problems (walls, residential lot boundaries, thick vegetation, and asphalt) only eight 2D-ERTs (Figure 2a) were carried out as planned, whereas the other three 2D-ERTs were integrated into and replaced by the 3D-ERTs (Figure 2a). Only the 2D-ERT05 and the two other carried out in the Chiusa stream and Riale stream riverbeds (2D-ERT03 and 2D-ERT07) reached investigation depths of 20 and $40 \mathrm{~m}$. For all the other 2D-ERT, the mean penetration depths ranged from 8 to $17 \mathrm{~m}$. Only the resistivity measurements were carried out along the $2 \mathrm{D}$ profiles.

In the second step, considering the limited investigation depth and taking into account that the 2D-ERT profiles were not as high performing in a complex environment with variations of water content and porosity changes (Fischanger et al. 2013), 12 3D-ERTs/IPTs were designed (Figure 2a). Using the 3D-ERT acquisitions (Loke and Barker 1996, Santarato et al. 2011), it was possible (i) to arrange the electrodes along nonlinear profiles around buildings, residential lot boundaries, and all the other obstacle; (ii) to increase the investigation depth up to $30-40 \mathrm{~m}$; and (iii) to optimise the acquisition sequence to enhance the sensitivity inside the 3D-ERT boundaries. Because of the logistical obstacles, only half of the 12 hypothesised that 3D-ERT were actually carried out, whereas 11 3D-ERT were designed and performed for a total of 17 3D-ERT. Both the resistivity and chargeability measurements were carried out in the 3D surveys.

All the ERTs/IPTs were implemented using the Iris SyscalPro 48 electrodes (10-channels receiver) sometimes joined with a 24-electrode external link. Given the dimensions of the sinkholes (some metres) and the hypothesis of a deep trigger phenomena (Intrieri et al. 2015, 2018), the electrode spacing was planned to be equal to $5 \mathrm{~m}$. Unfortunately, due to accessibility issues, the electrode spacing varied from 1 to $5 \mathrm{~m}$. After accounting for the advantages and limitations of each array configuration (Smith 1986; Loke and Barker 1996; Zhou et al. 2002; Dahlin and Zhou 2004; Szalai and Szarka 2008; Santarato et al. 2011; Samyn et al. 2014), the pole-dipole array was employed for both 2D-ERT and 3D-ERT measurements. This array combines consistent signal strength with a high resolution and large depth of investigation (Santarato et al. 2011). As is well known, the remote current electrode (B) has to be placed at a distance at least five times that of the largest A-M distance for each survey (with A being the current electrode near the potential dipole M-N). Unfortunately, in urban contexts, it is possible that the B electrode cannot be placed at the appropriate "infinite" distance (Santarato et al. 2011). In this case, we placed the remote pole as far away as possible. The most popular dipole-dipole array, based on current and voltage cables widely separated to enhance the lateral resolutions at shallow depths and to minimise electromagnetic inductive noise, was also applied. Also a Wenner-Schlumberger reciprocal array was used in the 2D-ERTs acquisitions. Each ERT/IPT acquisition sequence (i) was generated, including all the "common cable" and the forward and reverse "cross cable" quadripoles of both pole-dipole and dipole-dipole arrays; (ii) was filtered on the basis of the geometric factor (k), rejecting quadripoles with $\mathrm{k}>1500 \mathrm{a}$ (with a being the interelectrode distance); and (iii) was optimised for the 2D-ERT and 3D-ERT on the basis of the electrode geometry by means of the softwares ERTLab Sequencer and Electre Pro to take advantage of the multichannel instrument acquisition system (Santarato et al. 2011). This procedure resulted in a variable number of acquired data for each ERT. The acquired quadripoles are summarised in Table 1.

Table 1 Field data acquisition parameters.

\begin{tabular}{|c|c|}
\hline \multirow[t]{5}{*}{ 2D-ERT } & Device: Iris SyscalPro 48 el., 10 channels \\
\hline & Electrodes: 48 \\
\hline & Array: PD, DD, WSrec (customised sequence) \\
\hline & Electrode spacing: $1-5 \mathrm{~m}$ \\
\hline & Total apparent resistivity values: 24,423 \\
\hline \multirow[t]{5}{*}{ 3D-ERT } & $\begin{array}{l}\text { Device: Iris SyscalPro } 48 \text { el., } 10 \text { channels and } 24 \text { el. } \\
\text { external link }\end{array}$ \\
\hline & Electrodes: 72 \\
\hline & Array: PD (customised sequence) \\
\hline & Electrode spacing: $2-5 \mathrm{~m}$ \\
\hline & Total apparent resistivity values: 70,114 \\
\hline \multirow[t]{5}{*}{$\mathbf{H} / \mathbf{V}$} & Device: Tromino® \\
\hline & Sampling frequency: $256 \mathrm{~Hz}$ \\
\hline & Trace: $30 \mathrm{~min}$ \\
\hline & Single-station measures: 120 \\
\hline & Sections: 10 \\
\hline
\end{tabular}




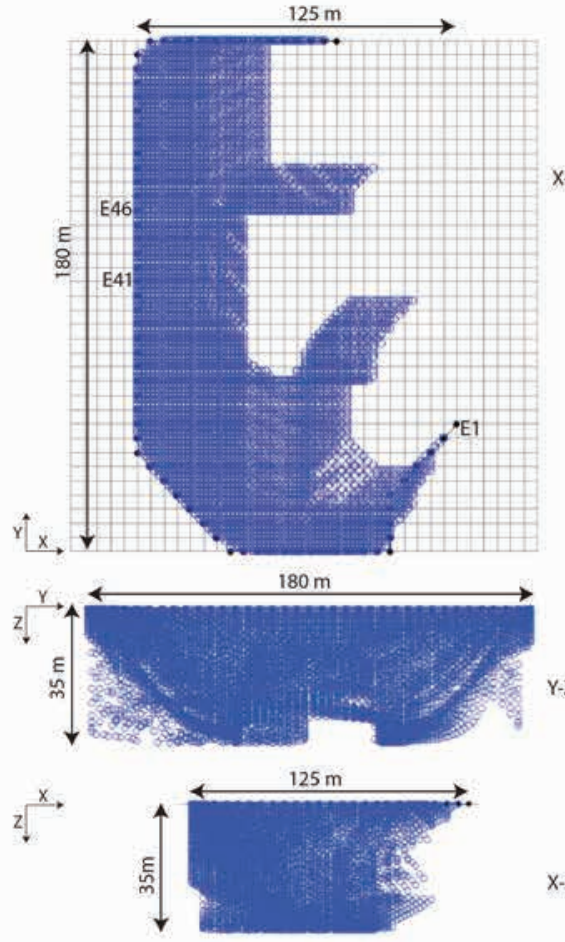

a)

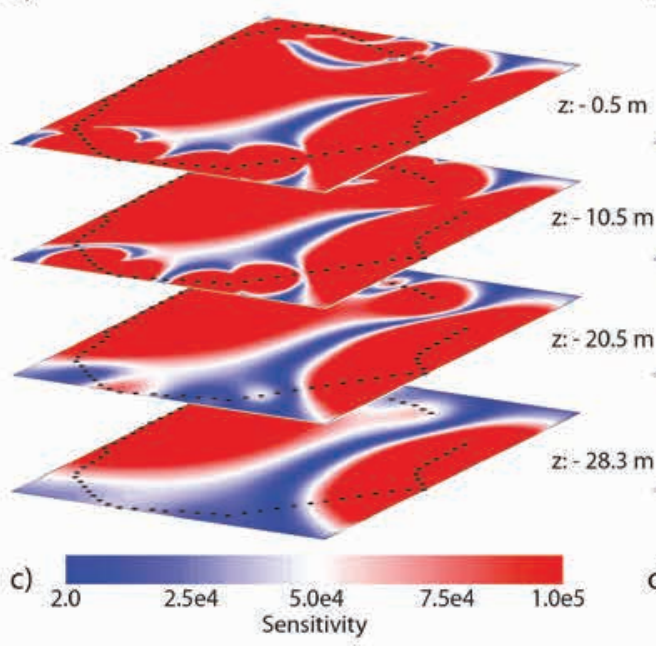

Note that the effectiveness of a 3D-ERT coverage is commonly studied by means of a sensitivity function. On the other hand, the apparent resistivity pseudo-plot conventionally shows each apparent resistivity datum in the XY plane at the midpoint defined by the average of the transmitting and receiving electrode coordinates. Moreover, in this graph, the apparent depth level of each plotted data point is increased on the basis of a geometric factor k. In Figure 3(a,b), the horizontal and vertical pseudo-plots of the planned and actual apparent resistivities, respectively, of one of the largest loop arrays (3D-ERT08) are shown as examples. The first pseudo-plot was created by the software employed to generate the acquisition sequence (ERTLab Sequencer) and does not take into account the true electrode
Figure 3 Horizontal $(X-Y$ planar view) and vertical $(Z-X$ and $Z-Y$ vertical views) views of a) the planned and b) actual apparent resistivity data distributions. The planned distribution was generated by means of the ERTLab Sequencer software and did not account for the true electrode locations. The actual distribution was produced by the inversion software (ERTLab) and takes into account the true electrode locations. In b), the filled black dots are the negative values; c) shows the sensitivity analysis of the whole dataset (3D-ERT08); d) shows the sensitivity analysis of one of the larger quadripoles (current electrode: E1; voltage electrodes: E41 and E46 highlighted in a) and b)). 
means of five Tromino® (Del Soldato et al. 2018; Pazzi et al. $2017 \mathrm{~b}$ ) so that the noise induced included in the measurements by the instrument are as reduced as possible (SESAME 2004). The acquisition parameters are summarised in Table 1 .

All the electrodes and the H/V single stations were georeferred using a Leica 1200 differential GPS in Real Time Kinematic mode. The mean 3D coordinate quality was roughly $2.0 \mathrm{~cm}$. Additionally, the same instrument and precision were employed to collect topographic data of the areas surrounded by the ERTs, in order to optimise the inversion procedure. The total number of acquired data was the function of the surface roughness (minimum collected points: 26 within the 3D-ERT07 boundaries; maximum collected points: 79 within the 3D-ERT09 boundaries).

\section{Data analysis}

The commercial software ErtLab ${ }^{\mathrm{TM}}$ (Geostudi Astier srl, Italy, and Multi-Phase Technologies, USA) was employed to invert the ERT data. This software (i) employs finite-element discretisation; (ii) implements an optimal data noise management (Cardarelli and Fischanger 2006; Fischanger et al. 2013) for Occam's regularisation (Constable, Parker and Constable 1987); (iii) has the ability to model the true remote electrode position by accounting for the effects of the B electrode when it is not placed at an appropriate "infinite" distance from the M-N dipole (Santarato et al. 2011); (iv) allows the exploration of the best electrode arrangements (i.e., the rotation of the electrode coordinates to achieve an electrode arrangement with a side as parallel as possible to the $X-Y$ axis) to reduce mesh parametrisation; (v) calculates the quality of an inversion while accounting for every data point affected by the Gaussian noise (i.e., the error that affects the field data) and minimizing the misfit function $\chi^{2}$ between the field and modelled data, as defined in Santarato $e t$ al. (2011); and (vi) allows setting a robust inversion to appropriately manage any noise during inversion by means of a dataweighting algorithm that allows the adaptive changes of the variance matrix after each iteration for those data points that are poorly fit by the model. Therefore, the reliability of the model is not influenced by the shape of the loop. The apparent resistivity value of the starting homogeneous half-space was chosen as the mean apparent resistivity value for each dataset. A noise percentage equal to 5 was chosen for each ERTs/IPTs.

The H/V traces were processed, as described in Pazzi et al. (2017b), by means of the Grilla® software (Castellaro 2016), and according to the SESAME (2004) criteria; only unambiguous peaks were considered for further study. The local shear velocity profiles were constructed via fitting a synthetic $\mathrm{H} / \mathrm{V}$ curve to the experimental one (Ibs-Von Seht and Wohlenberg 1999; Castellaro and Mulargia 2009b; Lotti et al. 2015; Del Soldato et al. 2016; Pazzi et al. 2017b). According to Castellaro and Mulargia (2009b) and Castellaro (2016), infinite synthetic models can fit an H/V curve when no constraints are imposed. Therefore, each acquisition was constrained with the first layer velocity measured, as explained in Pazzi et al. (2017b). Moreover, the porosity and soil density values reported in the literature (Reynolds 2011) were used to obtain the $\mathrm{V}_{\mathrm{s}}$ profile that best fit the experimental data. Additionally, the directionalities of each spectral peak (Del Gaudio et al. 2008; Pazzi et al. 2017a) were calculated by means of the same software. As shown in Pazzi et al. (2017b) and the reference therein, the dataset of the deepest impedance contrast depths and amplitudes was spatially interpolated in a GIS environment using the IDW geostatistical method to generate the thickness and peak amplitude maps. Among the possible alignments of the single-station measures, those parallel to the ERTs/IPTs electrodes were selected to generate the vertical cross-sections of the $\log (\mathrm{H} / \mathrm{V})$ values (Castellaro 2016; Pazzi et al. 2017b). The $\mathrm{H} / \mathrm{V}$ values acquired along these lines were converted as described in Castellaro (2016), moving from the frequency domain to the depth domain by means of the Ibs-von Seht and Wohlenberg (1999) simplified $V_{s}$-depth relations.

\section{RESULTS}

A total of 126,511 quadripoles were acquired. The 2D and 3D apparent resistivity datasets comprise 24,432 and 102,079 points, respectively. All the ERT/IPT inversions converged, meaning that the resistivity/chargeability models of the last inversion had a residual value lower than the $\chi^{2}$ value. The resistivity models resulting from the 2D-ERT inversions are shown in Figure 4. The 2D tomographies allowed to reach a mean depth of approximately $20 \mathrm{~m}$, with a minimum investigation depth value of $8 \mathrm{~m}$ obtained by the 2D-ERT10 and a maximum of $40 \mathrm{~m}$ for the 2D-ERT03. The results of the 3D survey are shown in Figure 5. The Figure was produced by combining the results of each 3D-ERT/IPT model in the Voxler 3D viewer software. Given the number of acquired quadripoles, it was not possible to invert all at the same time. Using the 3D surveys (Figure 5), it was possible to investigate a mean depth of approximately $30 \mathrm{~m}$. In particular, the minimum value was that of 3D-ERT05c $(3 \mathrm{~m})$, whereas the maximum one was obtained by 3D-ERT01 (40 m).

Generally, the mean resistivity values of the investigated areas ranged from 50 to $100 \Omega \mathrm{m}$. Greater resistivity values (>150 $\Omega \mathrm{m}$, red areas in Figure 4 and Figure 5a) were detected in some electrical tomographies as proof of the presence of less conductive materials, both at shallow and greater depths. Conductive areas (black dashed areas in Figure 4) were detected at shallow depths (up to $15 \mathrm{~m}$ ). Generally, chargeability is roughly zero or is very low in the study area (Figure 5b), as expected for the alluvial deposits with low clay contents or areas with subsoil voids filled with air (Murali and Patangay 2006).

The distribution of seismic noise single-station measurements is shown in Figure 2b. Note that, (i) a trace recorded on a homogenous rock without a cover layer has a flat $\mathrm{H} / \mathrm{V}$ curve, and no seismic wave amplification is expected; (ii) a trace recorded over a single-layer stratigraphy (a sedimentary cover overlaying a seismic bedrock) gives an $\mathrm{H} / \mathrm{V}$ curve with one peak; (iii) in a single-layer stratigraphy, the $\mathrm{H} / \mathrm{V}$ peak frequency could be 
related to the thickness $\mathrm{h}$ of the sedimentary layer and its shear velocity $\mathrm{V}_{\mathrm{s}}$ according to the well-known equation $\mathrm{F}=\mathrm{V}_{\mathrm{s}} / 4 \mathrm{~h}$; (iv) the $n$-peaks in the $\mathrm{H} / \mathrm{V}$ curve are caused by $\mathrm{n}+1$ layers of different lithologies; ( $v$ ) by constraining the shallow subsoil stratigraphy or the $\mathrm{V}_{\mathrm{s}}$ of the first layer, it is possible to model the $\mathrm{V}_{\mathrm{s}}$ profile by obtaining $\mathrm{h}_{\mathrm{i}}$ (with $\mathrm{i}=1,2, \ldots \mathrm{n}$ ) and $\mathrm{V}_{\mathrm{si}}$ (with $\mathrm{i}=1,2, \ldots \mathrm{n}+1$ ); and (vi) the high-frequency peaks in the $\mathrm{H} / \mathrm{V}$ curve are related to shallow depth interfaces, whereas the lowfrequency $\mathrm{H} / \mathrm{V}$ peaks are related to the deep interfaces (Castellaro 2016 and reference within; Pazzi et al. 2017b).
For the whole seismic dataset, three main frequency ranges associated with just as many natural discontinuities were recognised. Using the equation illustrated above (point c), it was possible to define the related depth and $\mathrm{V}_{\mathrm{s}}$ ranges. A representative selection of the results obtained from the H/V analysis is shown in Figure 6. The first peak (with a frequency range of $60-90 \mathrm{~Hz}$, Figure $6 \mathrm{~d}$ ) can be related to the shallow discontinuity between the aerated/weathered surface layer $\left(\mathrm{V}_{\mathrm{s}}\right.$ range of $100-250 \mathrm{~m} / \mathrm{s})$ and the alluvial deposits $\left(\mathrm{V}_{\mathrm{s}}\right.$ range of 400 $600 \mathrm{~m} / \mathrm{s}$ ) at a mean depth of approximately $0.2-1.5 \mathrm{~m}$ (Figure 7).

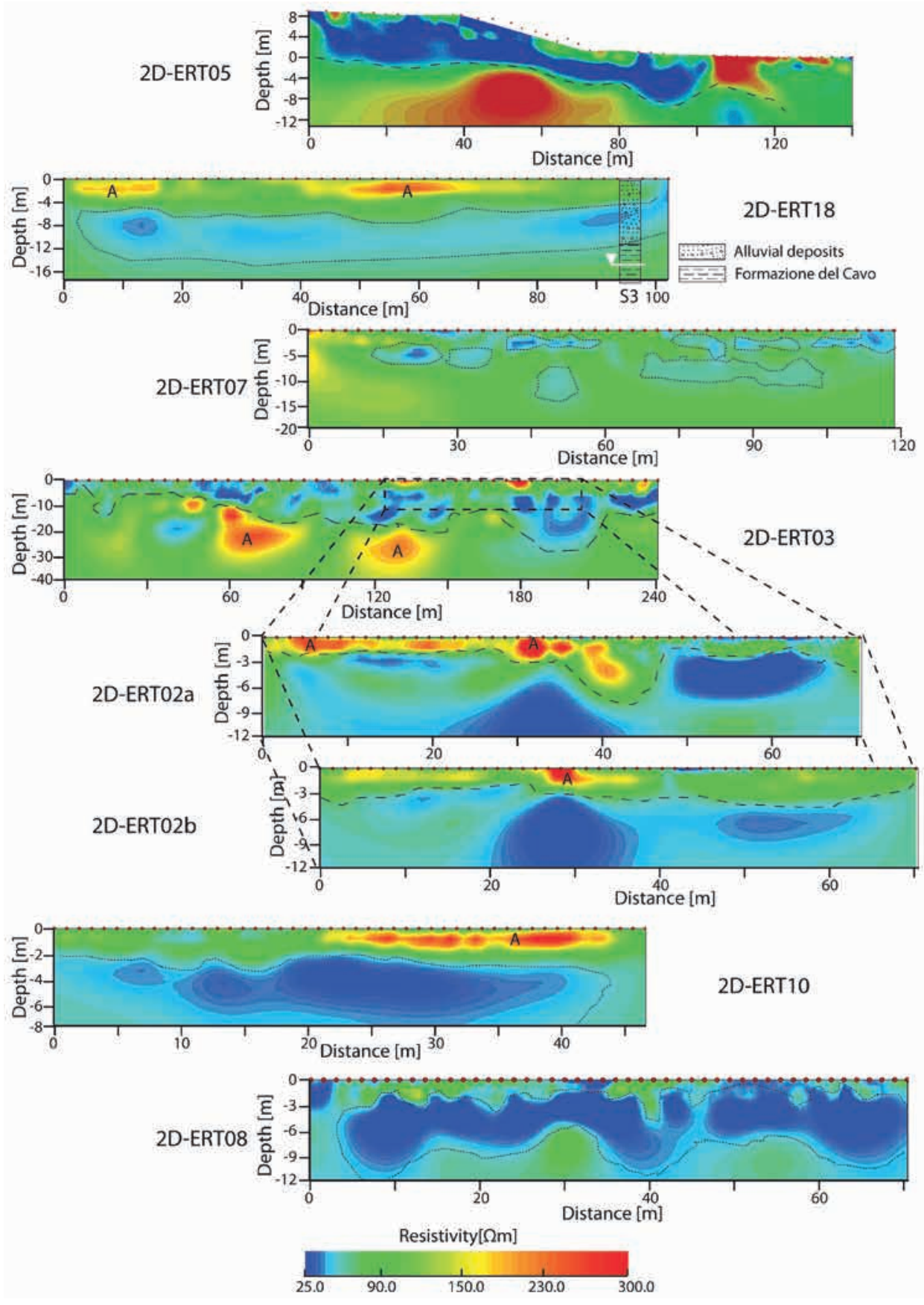

Figure 4 Resistivity sections derived from 2D-ERTs. For their locations, refer to Figure 2a. Since the topography is quite flat, $0 \mathrm{~m}$ means the surface, and all the vertical scales show depth from this surface. In the 2D-ERT05, zero is the same surface level as in all the other 2D-ERTs. The dashed black line in 2D-ERT05 and 2D-ERT03 could be the interface between the alluvium deposit and substrate (maximum depth of the paleochannel influence area: see discussion paragraph). In all 2D-ERTs, the dotted black lines highlight the conductive areas interpreted as paleochannels. 

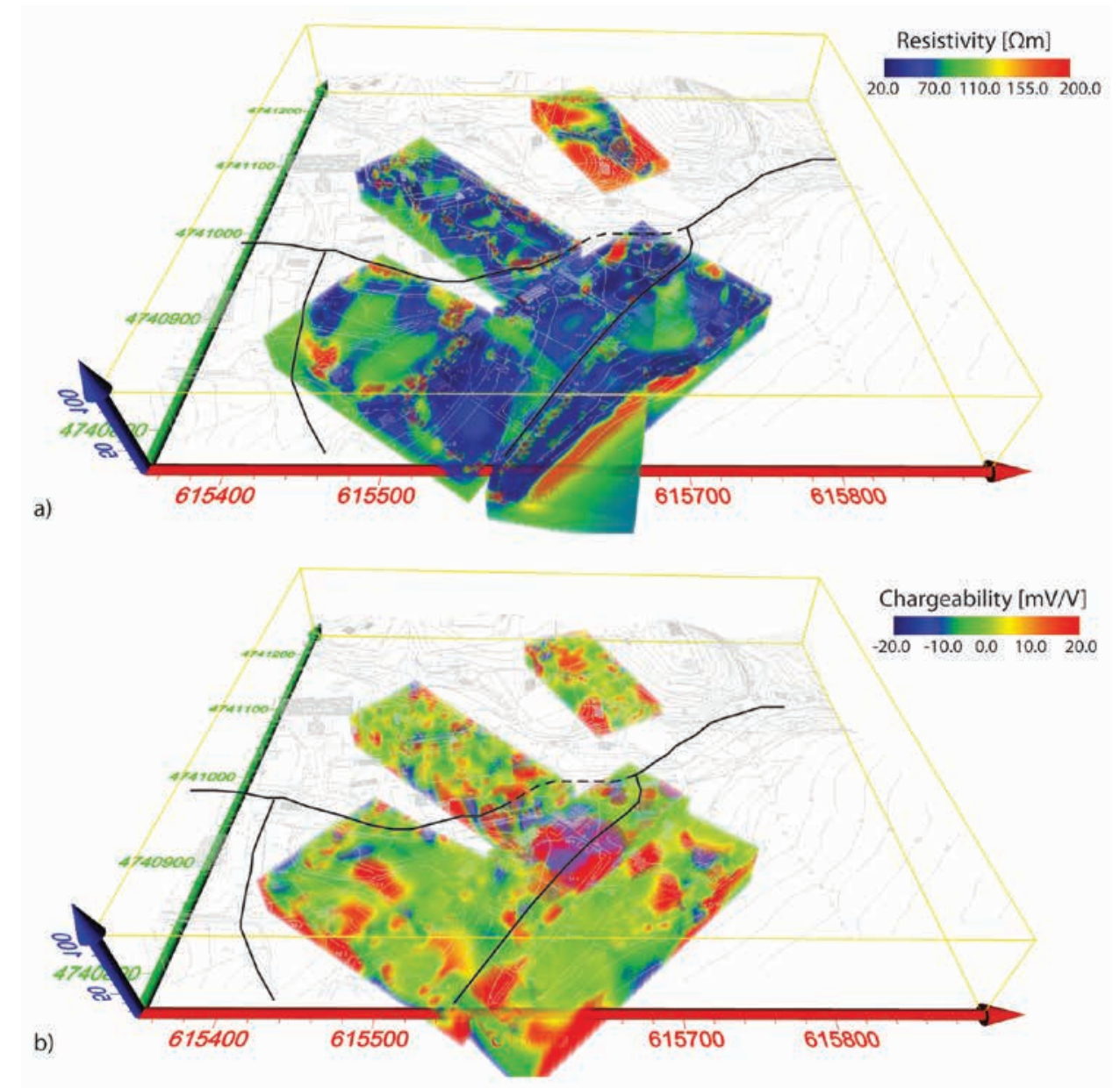

Figure 5 Three-dimensional view of a) the resistivity and b) the chargeability of the area obtained by combining the results of each 3D-ERT/IPT model in the Voxler $3 \mathrm{D}$ viewer software. The solid black line is the pre-existing provincial SP26 road that is still open to traffic and the new bypass, whereas the dashed black line is the road closed to traffic after the 2013 sinkhole.
A second interface was identified at depths ranging from 1.5 to $7.6 \mathrm{~m}$ (at a frequency of $12-30 \mathrm{~Hz}$, Figure 6c), corresponding to the transition from alluvium to the locally weathered claystone (Formazione del Cavo formation; $\mathrm{V}_{\mathrm{s}}$ range of 800$1000 \mathrm{~m} / \mathrm{s}$ ) (Figure 7). Finally, a third peak is characterised by the frequency range of $3.5-7.8 \mathrm{~Hz}$ (Figure $6 \mathrm{~b}$ ), identifying the seismic interface between the claystone and the seismic bedrock (Brecce di Rialbano formation; $\mathrm{V}_{\mathrm{s}}$ higher than $1200 \mathrm{~m} / \mathrm{s}$ ), at approximately $10.5-35 \mathrm{~m}$ (Figure 7). For the aim of the present work, only the third peak $(3.5-7.8 \mathrm{~Hz})$ was considered for the following analysis since it corresponds to the stratigraphic limit between the seismic bedrock and the other materials.

\section{DISCUSSION}

To evaluate the subsoil void susceptibility of the area around the "Il Piano" road system, the results of the integrated geophysical survey were interpreted by accounting for the large overlaps in the density, ER, and seismic wave velocity values (Telford, Geldart and Sheriff 1990; Reynolds 2011). First, the geoelectrical and seismic results were analysed and evaluated based on the geological context and the stratigraphies obtained from the bore- holes carried out along the SP26 road after the 2013 sinkhole. A simplified view of these stratigraphies is shown in Figure $7 b$ (see Figure $2 \mathrm{~b}$ for the boreholes location). After accounting for the results shown in Figure 4 (2D-ERT18) and Figure 7, the alluvial deposit layer is mainly inhomogeneous (i.e., there are both low and high resistive anomalies). Moreover, in the stratigraphic boreholes, the water table was found to exist in the Formazione del Cavo formation at a minimum of a 20-m depth, whereas the 2D/3D-ERTs highlight the shallow conductive areas. This is a sign of a complex ground water drainage network (Intrieri et al. 2018).

The reliability of the loop arrays in this urban environment and their high resolution for shallow depths were evaluated by acquiring two tomographies from among all the 3D-ERTs (the 3D-ERT06b and the 3D-ERT04b) with a grid-shaped layout. Also, 2D-ERT2a and 2D-ERT2b (interelectrode distance: $1.5 \mathrm{~m}$ ) were acquired at distances of $2 \mathrm{~m}$ for the same purpose. After accounting for the high resolutions of the loop ERTs compared with the grid-shaped ones, all the other ERTs were carried out by means of a loop array. Only 3D-ERT05a, 3D-ERT3b, 3D-ERT3c and 3D-ERT13a, 3D-ERT13b were acquired by means of the grid-shaped array due to logistical problems. To cover the same 
a)
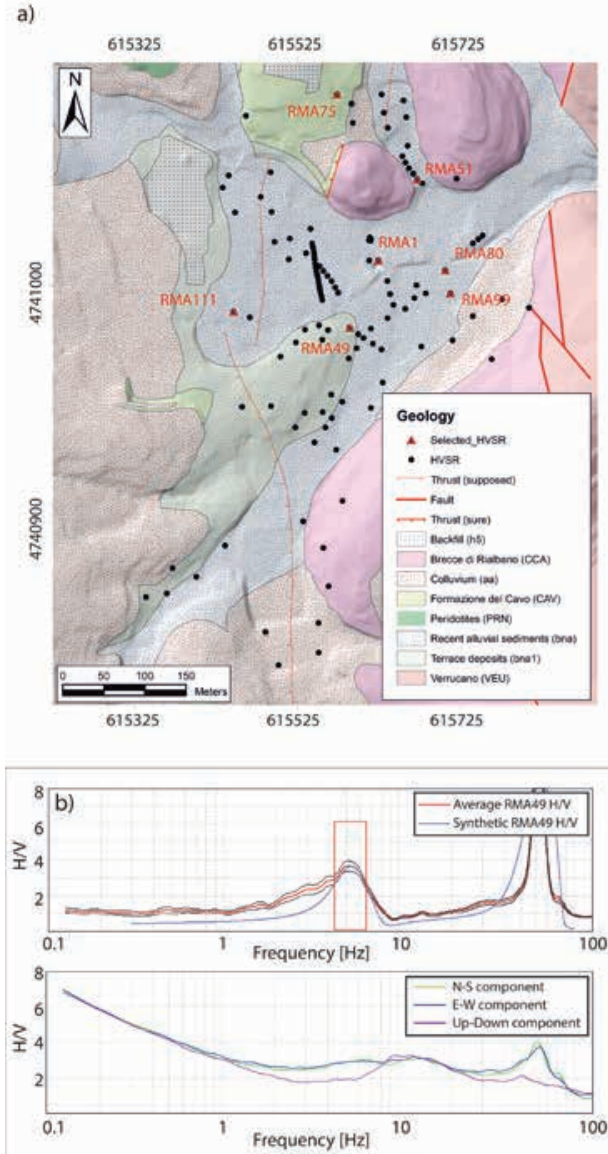

f)
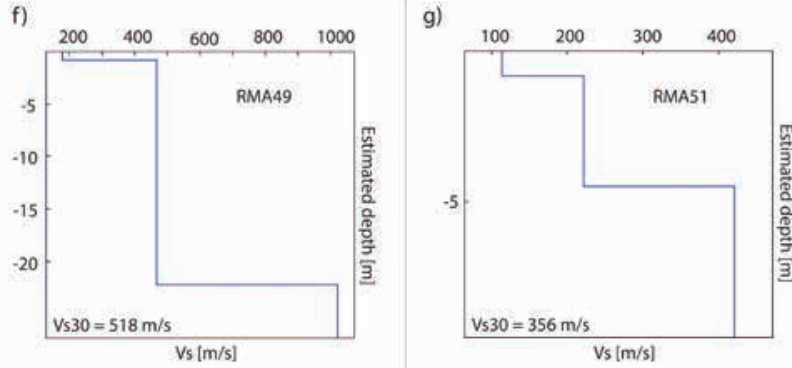

area, a loop array with fewer electrodes should be implemented for a lower total depth of exploration. Therefore, the advantages of the 3D loop array compared with the grid-shaped one are as follows: (i) this array is less time consuming, (ii) the penetration depth is greater, (iii) the total number of acquired apparent resistivity data is higher, (iv) this array does not suffer from a lack of data along the short side of the grid, and (v) the resolution of the inversion results is mainly influenced by the total number of acquired apparent resistivity data (like those in a $2 \mathrm{D}$ inversion) and not by the shape of the loop array (and therefore the covered area).

Ten 2D vertical cross-sections of the $\log (\mathrm{H} / \mathrm{V})$ values were generated (Castellaro 2016; Pazzi et al. 2017b) by interpolating the H/V single-station measures of selected alignments (Figure $2 \mathrm{~b}$ ). These $2 \mathrm{D}$ profiles were compared with the resistiv-
Figure 6 The most significant $\mathrm{H} / \mathrm{V}$ results: a) the localisation on the geological map of the selected $\mathrm{H} / \mathrm{V}$ single-station measurements (red triangles). The black dots are the whole H/V measurements. b) Trace (RMA49) with lower peaks of 3.5-7.8 Hz; c) trace (RMA51) with a second peak between $12 \mathrm{~Hz}$ and $30 \mathrm{~Hz}$; d) trace (RMA111) with the highest peak between $60 \mathrm{~Hz}$ and $90 \mathrm{~Hz}$; e) flat traces (RMA75) acquired on the outcropping bedrock. In b) to e), the upper curves are the acquired mean H/V (red line) with its standard deviation (black lines) and the modelled mean H/V (light blue line), whereas the lower are the three spectral components. f), g), and h) are the modelled $\mathrm{V}_{\mathrm{s}}$ profiles that generate the modelled mean H/V curves of RMA49, RMA51, and RMA111, respectively. Traces RMA01, RMA80, and RMA99 are shown in Figure 10. h)

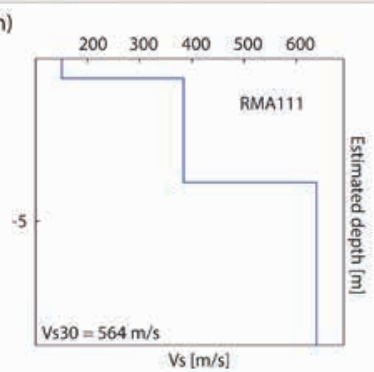

ity or chargeability sections extracted from the ERTs/IPTs. These sections were also chosen to avoid utilities and foundations, since the nonconductive or conductive masses that are off to the side of a line can result in misinterpreted structures appearing to occur beneath profile line depths comparable to the offline distances of causative structures (Dobecki 2010).

Figure 8 shows six examples of the elaborate $\mathrm{H} / \mathrm{V}$ vertical cross-sections in which warm colours (from green to orange) are associated with the positive acoustic impedance contrasts related to the transitions between materials with different seismic wave velocities (from lower to higher). Cold colours (dark blue in Figure 8) identify the negative impedance contrasts and correspond to velocity inversions (Castellaro and Mulargia 2009a). Light blue areas are related to the absences of impedance contrasts. 
Generally, the mean resistivity values of the investigated areas range from 50 to $100 \Omega \mathrm{m}$, which is consistent with the Quaternary alluvial deposit resistivity values proposed by Reynolds (2011). The shallow conductive materials associated with saturated high-porosity materials were interpreted as saturated gravel and dry sand (resistivity $<70 \Omega \mathrm{m}$ ). However, the deeper resistive anomalies were related to brecciated dolomitic limestones and very weathered metamorphosed siltstones, probably from the Brecce di Rialbano and Formazione del Cavo formations (Figure 8(a,c)). The IP data were interpreted by accounting for the resistivity results. The negative IP anomaly in section 1 (2D-ERT05 or 3D-ERT06b, Figure 8a) is too small to be interpreted as being produced by lateral inhomogeneities (Milsom and Eriksen 2011) due to the narrow morphology of the area and is highlighted by the deep resistive anomaly in the ERT section. This small negative IP anomaly was probably caused by the power line that crossed the section (Figure 2). The positive IP anomaly in Section 5 (Figure 8b) was caused by lateral inhomogeneities. All the other positive IP anomalies could be interpreted as areas with higher clay contents. Thus, these IP anomalies are mainly caused by membrane polarisation. The shallow negative IP anomalies could also be produced by layered environments where the surface and deeper layers are more conductive than those in between. These negative anomalies, when characterised by low resistivity values, were interpreted as paleochannels.

The Quaternary alluvium deposits of the study area are mainly characterised by a horizontal medium-to-fine-grained layer with an increasing particle size upwards according to the detailed stratigraphies carried out along the SP26 road. The comparisons of the resistivity, chargeability, and vertical H/V crosssections (Figure 8) show that (i) the alluvium deposits have homogeneous electrical behaviours, (ii) the more conductive zones at shallow depths do not have the high chargeability that could be related to low clay contents of fine materials, and (iii) the seismic wave velocities gradually increase with depth, resulting in a homogenous value of the $\log (\mathrm{H} / \mathrm{V})$. There is no evidence to ascribe the marked heterogeneity to an anthropogenic origin (i.e., subservice). Therefore, the highlighted heterogeneity could be related to the alternation of variable grain size deposits, heteropic facies (i.e., facies that replace one another laterally in deposits of the same age or characterised by different rock types), interdigitations, and lenticular bodies of gravel and sand associable with paleochannels. In the $\mathrm{H} / \mathrm{V}$ vertical cross-sections, these paleochannels are marked by shallow velocity inversions. This natural heterogeneity also seems to be more distinct in the easternmost portion of "Il Piano", where the slope angle can be as low as zero and where, in recent and Holocene epochs,
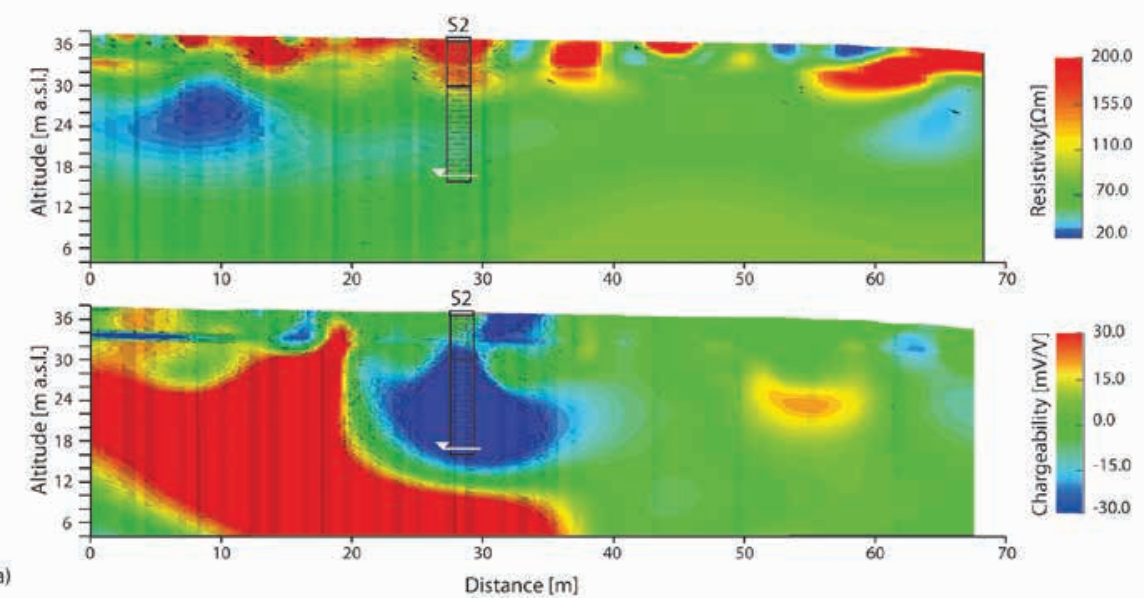

a)

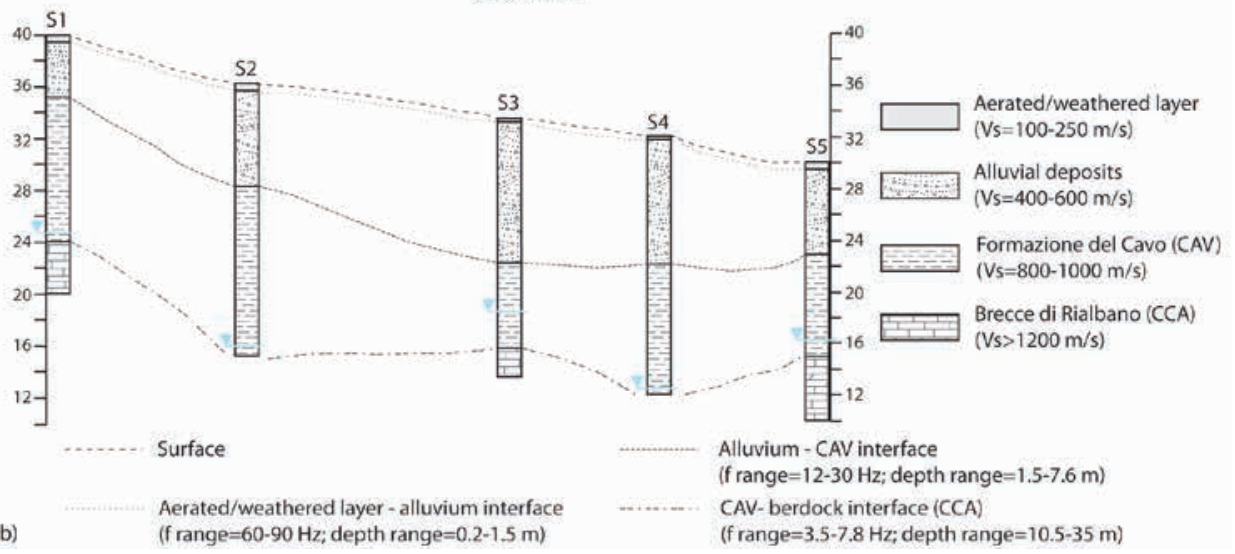

Figure 7 a) Comparison between a $2 \mathrm{D}$ vertical section extract from the 3D-ERT04 (Figure 2a) and one parallel to SP26 and the boreholes of $\log$ S2. b) Simplified stratigraphy section (not to scale along the $X$ direction) reconstructed from the five boreholes available along SP26. For the locations, see Figure 2b. 


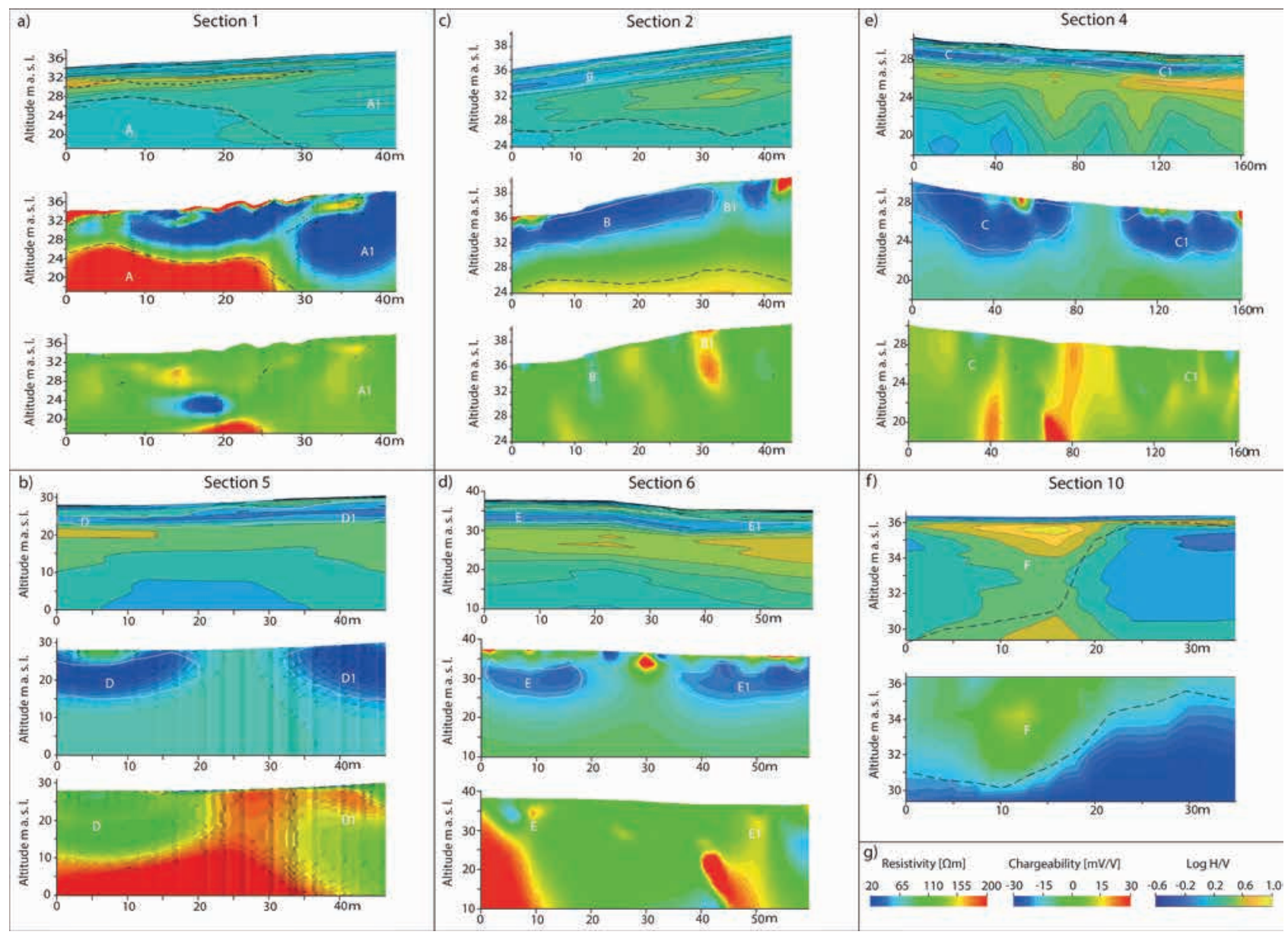

Figure 8 a) Section 1; b) Section 5; c) Section 2; d) Section 6; e) Section 4 H/V vertical cross-section, 2D section of resistivity, and chargeability; f) section $10 \mathrm{H} / \mathrm{V}$ vertical cross-section and 2D resistivity section. g) $\log (\mathrm{H} / \mathrm{V})$, resistivity, and chargeability scale bars. The dotted white lines highlight conductive bodies (also underlined by letters) interpreted as paleochannels. Dashed black lines emphasize the interface between alluvium and substratum.

the superficial streams produced large quantities of depositional and erosional materials.

Subsuperficial water circulation could be responsible for surface instabilities (Reitz and Eskridge 1977; Newton and Mark Tanner 1987). During heavy rain events, groundwater flow regime may switch from laminar to turbulent. Thus, fine sediments may be eroded from the alluvium, and subsoil voids may become enlarged, even migrating to the surface. Therefore, it is important to reconstruct the paleochannels and delimit their influence areas. The potentialities of interpolating single-station measurements acquired along lines to detect paleochannels (shallow seismic waves velocity inversion) were shown via comparisons between the vertical $\mathrm{H} / \mathrm{V}$ cross-sections and the resistivity sections. However, it was not possible to use the seismic results to perform a $3 \mathrm{D}$ reconstruction of the anomalies. Consequently, in the study area, the paleochannel influences on the area boundaries (i.e., the area filled with black lines in Figure 9) were reconstructed by accounting for only the electrical anomalies. When the H/V single-station measurement interpolations could be performed in both the $X$ and $Y$ directions with a low confidence interval, this passive technique is useful for reconstructing the 3D subsoil anomalies.

The peak amplitude map (Figure 9a) obtained by the IDW interpolation of the $\mathrm{H} / \mathrm{V}$ peak amplitudes shows that the area surrounding the road system and delimited as the paleochannel influence area has the highest values. The "real" site amplification factors may not be confidently derived from ambient noise (Del Gaudio et al. 2014). However, the peak amplitude is a good estimator of the soil/bedrock stratigraphic effects. In other words, the higher the peak amplitude, the higher the seismic acoustic impedance contrast between the soil and bedrock. Consequently, areas with high $\mathrm{H} / \mathrm{V}$ amplitudes are more prone to seismic amplification and resonance effects (Del Gaudio et al. 2014). The thickness of the alluvium was also reconstructed. Figure $9 \mathrm{~b}$ shows that the whole road system developed in the area with the highest value. This thickness corresponds to the maximum paleochannel depth delimited in 2D-ERT03 and 2D-ERT05 (Figure 4) via a dashed black line. Thus, the paleochannel-influenced area (i.e., the area filled with black lines) is the main hazardous area not only with respect to the subsoil 
water circulation but also to the seismic amplification/resonance effects and the alluvial deposit thickness. One potential solution to restore the SP26 road would be a bridge anchored to the substrate (30- to 40-m depth).

The H/V directivity could be affected by topographic effects. Open or filled sinkholes are "topographic" anomalies since the seismic waves could be affected by distortion effects. We decided to perform some measurements (RMA2, RMA3, RMA10, RMA12, RMA13, RMA14, RMA15, RMA16, RMA19, RMA79, and RMA99) near known sinkholes to investigate where there was a "sinkhole indicator" in the H/V curve. An analysis of the seismic noise directionality was also carried out in order to identify the eventual topographic amplification or de-amplification effects due to the sinkholes. The directional analysis did not highlight any evidence strictly connected to the presence of the sinkholes (Figure 10).

According to Intrieri et al. (2015), the main hazardous area was supposed to be related to the presence of caves in the rock basement (Brecce di Rialbano formation). The whole integrated geophysical survey was therefore planned on the basis of this hypothesis. The main results of a hydrogeological survey carried out in the study area at the same time as this geophysi-
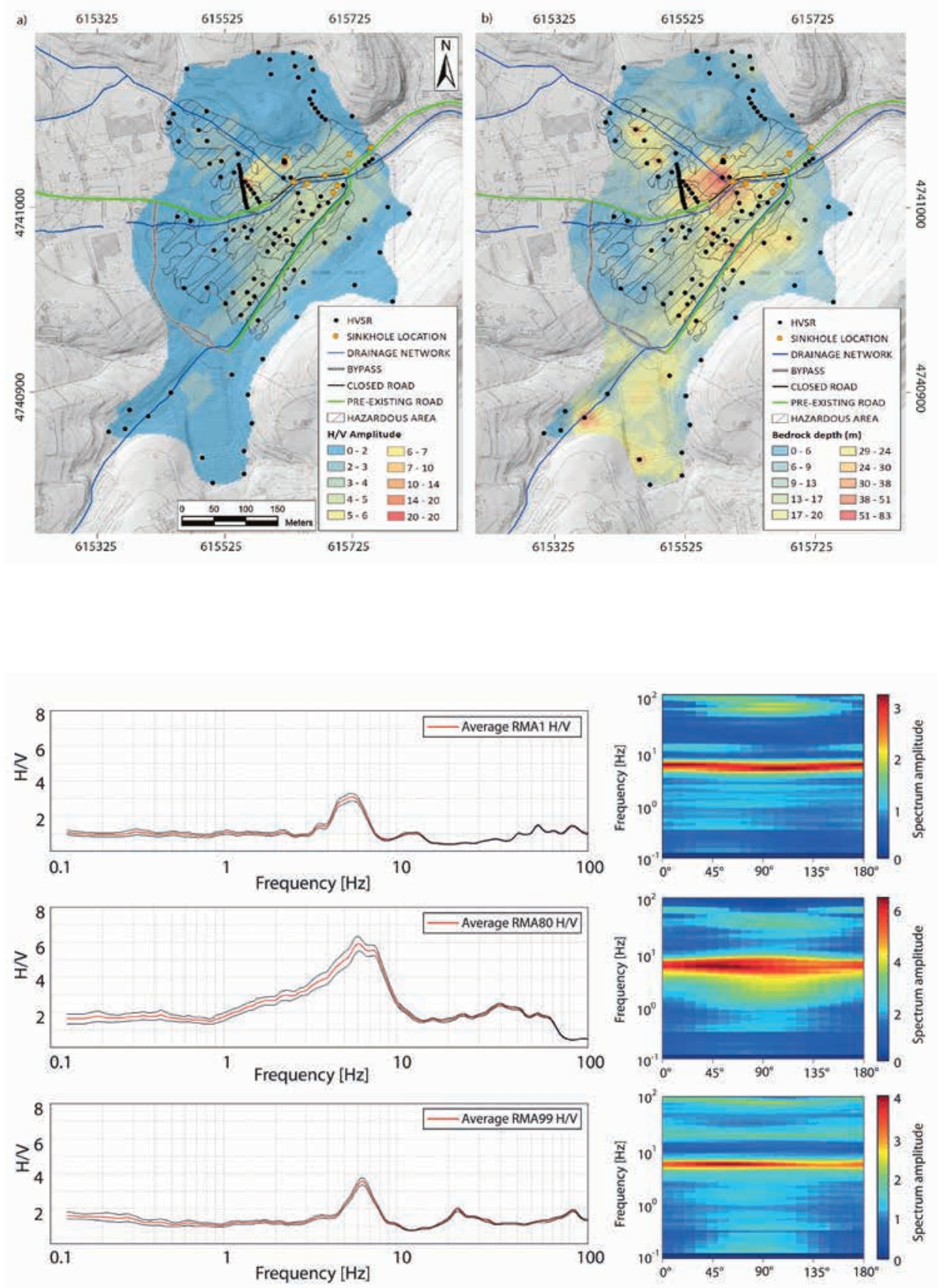

Figure 9 a) H/V peak amplitude map and b) alluvium deposit thickness or bedrock depth map obtained by the IDW interpolation of the peak amplitudes and depths associated with the lowest peaks. The black dots are the whole H/V measures. The black line is the provincial road "SP26", which was closed to traffic after the 2013 sinkhole; the green line shows the pre-existing road system that is still open to traffic; the grey line shows the new bypass; and the blue lines show the drainage network. Moreover, the orange dots are the sinkholes that occurred between 2008 and 2014. The area highlighted with black lines is the paleochannels influence area.

Figure $10 \mathrm{H} / \mathrm{V}$ curves and directionalities of three measurements (RMA01, RMA80, and RMA99; see Figure 6 for their locations) carried out near the sinkholes. 
cal survey showed that the delimited paleochannel-influenced area is also affected by an ineffective maintenance of the superficial and shallow drainage networks (Intrieri et al. 2018). According to earlier road construction projects, the road was built without any anchor to the hard substrate. Therefore, this work demonstrates that the main hazard of the road system is related to the subsuperficial water circulation in the paleochannels mainly located in the areas with the largest thickness of the alluvium deposit.

\section{CONCLUSIONS}

An integrated geophysical survey was carried out to assess the subsoil void susceptibility along and near the SP26, which was closed to traffic after the 2013 sinkhole disaster. The 2D-/3DERTs, 3D-IPTs and H/V single-station measurements allow a reliable characterisation of the geology and the electrical behaviour of the materials in this area. In particular, shallow conductive bodies, also characterised by the inversion of the seismic velocity, were interpreted as paleochannels. These channels are lenticular sand and gravel bodies within the sandy silt layer. Moreover, the $\mathrm{H} / \mathrm{V}$ analysis permitted the estimation of the mean thickness of the alluvium and its peak amplitude. The results show that both the thickness and amplitude have the highest values below the road system and in the area surrounding the road system. The delimited paleochannel-influenced area is more hazardous with respect to the subsuperficial water circulation and is also more prone to seismic amplification. Therefore, some general countermeasures for mitigating subsoil void susceptibility and overcoming environmental and infrastructure problems may be identified (e.g., the reorganisation of the superficial drainage system or the improvement of the superficial water management). Moreover, the restoration of the old SP26 will be possible only via the realisation of specific infrastructural and conservative works like the replacement of the road with a bridge anchored to the substrate.

\section{ACKNOWLEDGEMENTS}

This project was funded by the Municipality of Rio Marina and the Municipality of Rio nell'Elba thanks to the Tuscany Region Financing (grant number: Rep. 42/2015). The authors would like to thank Gabriele Bicocchi, Federica Bardi, Federico Marini, Tommaso Carlà, Katia Fontanelli, Niccolò Galfo, Lorenzo Giardi, and Emanuele Intrieri for their fieldwork support and the inhabitants and the local authorities for their availabilities. The authors are also very grateful to the three anonymous reviewers and to the guest editor for providing the very useful comments that allowed the improvement of the scientific quality of the manuscript.

\section{REFERENCES}

Barberi F., Brandi G.P., Giglia G., Innocenti F., Marinelli G., Raggi G. et al. 1969. Isola d'Elba, Foglio 126. Firenze: Carta Geologica d'Italia Servizio Geologico d'Italia, E.I.R.A.
Barberi F., Dallan L., Franzini M., Giglia G., Innocenti F., Marinelli G. et al. 1967. Carta geologica dell'Isola d'Elba alla scala 1:25.000. Firenze: E.I.R.A.

Bishop I., Styles P., Emsley S.J. and Ferguson N.S. 1997. The detection of cavities using the microgravity techniques: case histories from mining and karstic environments. Engineering Geology Special Publications 12, 153-166.

Bortolotti V., Fazzuoli M., Pandeli E., Principi G., Babbini A. and Corti S. 2001. Geology of Central and Eastern Elba Island, Italy. Ofioliti 26(2), 97-150.

Butler D.K. 1984. Microgravimetric and gravity gradient techniques for detection of subsurface cavities. Geophysics 49, 1084-1096.

Caramanna G., Ciotoli G. and Nisio S. 2008. A review of natural sinkhole phenomena in Italian plain areas. Natural Hazards 45(2), 145172.

Cardarelli E., Cercato M., Cerreto A. and Di Filippo G. 2010. Electrical resistivity and seismic refraction tomography to detect buried cavities. Geophysical Prospecting 58, 685-695.

Cardarelli E., Cercato M., De Donno G. and Di Filippo G. 2014. Detection and imaging of piping sinkhole by integrated geophysical methods. Near surface Geophysics 12, 439-450.

Cardarelli E. and Fischanger F. 2006. 2D data modelling by electrical resistivity tomography for complex subsurface geology. Geophysical Prospecting 54, 121-133.

Castellaro S. 2016. The complementarity of H/V and dispersion curves. Geophysics 81, T323-T338.

Castellaro S. and Mulargia F. 2009a. The effect of velocity inversions on H/V. Pure and Applied Geophysics 166, 567-592.

Castellaro S. and Mulargia F. 2009b. $\mathrm{V}_{\mathrm{s} 30}$ estimates using constrained $\mathrm{H} / \mathrm{V}$ measurements. Bulletin of the Seismological Society of America 99, 761-773.

Chico R.J. 1964. Detection of caves by gravimetry. Speleology 1, 101108.

Constable S.C., Parker R.L. and Constable C.G. 1987. Occam's inversion: a practical algorithm for generating smooth models from electromagnetic sounding data. Geophysics 52, 289-300.

Dabas M., Camerlynck C. and Camps P.F.I. 2000. Simultaneous use of electrostatic quadrupole and GPR in urban context: investigation of the basement of the Cathedral of Girona (Catalunya, Spain). Geophysics 65, 526-532.

Dahlin T. and Zhou B. 2004. A numerical comparison of 2D resistivity imaging with ten electrode arrays. Geophysical Prospecting 52, 379-398.

Del Gaudio V., Coccia S., Wasowski J., Gallipoli M.R. and Mucciarelli M. 2008. Detection of directivity in seismic site response from microtremor spectral analysis. Natural Hazards and Earth System Sciences 8, 751-762.

Del Gaudio V., Muscillo S. and Wasowski J. 2014. What we can learn about slope response to earthquake from ambient noise analysis: an overview. Engineering Geology 182, 182-200.

Del Soldato M., Pazzi V., Segoni S., De Vita P., Tofani V. and Moretti S. 2018. Spatial modeling of depth to bedrock in peri-volcanic areas of Campania (southern Italy). Earth Surface Processes and Landforms, doi; 10.1002/esp.4350.

Del Soldato M., Segoni S., De Vita P., Pazzi V., Tofani V. and Moretti S. 2016. Thickness model of pyroclastic soils along mountain slopes of Campania (southern Italy). In: Landslides and Engineered Slopes. Experience, Theory and Practice. (eds Aversa et al.), pp. 797-804. Associazione GEotecnica Italaian, Rome, Italy. ISBN:978-1-13802988-0.

Dobecki T.L. 2010. Sinkholes and pitfalls in urban geophysics. The Leading Edge 29, 944-951.

Dobecki T.L. and Upchurch S.B. 2006. Geophysical application to detect sinkholes and ground subsidence. The Leading Edge 25(3), 336-341. 
Ezersky M. 2008. Geoelectric structure of the Ein Gedi sinkhole occurrence site at the Dead Sea shore in Israel. Journal of Applied Geophysics 64, 56-69.

Ezersky M.G., Bodet L., Akawwi E., Al-Zoubi A.S., Camerlynck C., Dhemaied A. et al. 2013. Seismic surface-wave prospecting methods for sinkhole hazard assessment along the Dead Sea Shoreline. Journal of Environmental and Engineering Geophysics 18, 233-253.

Fäh D., Kind F. and Giardini D. 2001. A theoretical investigation of average H/V ratios. Geophysical Journal International 145, 535-549.

Fairbridge R.W. 1968. The Encyclopaedia of Geomorphology. New York: Reinhold Book Corporation.

Fenning P.J., McCann D. and Veness K. 1994. Urban geophysicsSeeking the difficult and hidden. Proceedings of the Symposium on the Application of Geophysics to Engineering and Environmental Problems, pp. 529-541. Environmental and Engineering Geophysical Society.

Ferrara G. and Tonarini S. 1985. Radiometric geochronology in Tuscany. Result and problems. Rendiconti - Societa Italiana di Mineralogia e Petrologia, 40, 11-124.

Fischanger F., Morelli G., Ranieri G., Santarato G. and Occhi M. 2013. 4D cross-borehole electrical resistivity tomography to control resin injection for ground stabilization: a case history in Venice (Italy). Near Surface Geophysics 11, 41-50.

Giampaolo V., Capozzoli L., Grimaldi S. and Rizzo E. 2016. Sinkhole risk assessment by ERT: the case study of Sirino Lake. Geomorphology 253, 1-9.

Henderson R. 1992. Urban geophysics-A review. Exploration Geophysics 23, 531-542.

Herak M. 2008. The use of ambient noise for building and soil characterization. In: Increasing Seismic Safety by Combining Engineering Technologies and Seismological Data, (eds M. Mucciarelli, M. Herak and J. Cassidy), pp. 1-138. NATO Science for Peace and Security, Series C: Environmental Security, Springer Netherlands.

Ibs-Von Seht M. and Wohlenberg J. 1999. Microtremor measurements used to map thickness of soft sediments. Bulletin of the Seismological Society of America 89, 250-259.

Intrieri E., Fontanelli K., Bardi F., Marini F., Carlà T., Pazzi V. et al. 2018. Definition of sinkhole triggers and susceptibility based on hydrogeomorphological analyses. Environmental Earth Sciences 77(4). https://doi.org/10.1007/s12665-017-7179-3.

Intrieri E., Gigli G., Nocentini M., Lombardi L., Mugnai F., Fidolini F. et al. 2015. Sinkhole monitoring and early warning: an experimental and successful GB-InSAR application. Geomorphology 241, 304314.

ISPRA 2015. Carta geologica dell'Isola d'Elba. http://sgi1.isprambiente. it/website/isolaelbageo/carta_geologica_isola_elba.htm.

Ivanov J., Leitner B., Shefchik W., Tyler Shwenk J. and Peterie L.P. 2013. Evaluating hazards at salt cavern sites using multichannel analysis of surface waves. The Leading Edge 3, 298-305.

Jardani A., Dupont J.P. and Revil A. 2006. Self-potential signals associated with preferential groundwater flow pathways in sinkholes. Journal of Geophysical Research 111(B9).

Kaufmann G. 2014. Geophysical mapping of solution and collapse sinkholes. Journal of Applied Geophysics 111, 271-288.

Krawczyk C.M., Polom U. and Beilecke T. 2013. Shear-wave reflection seismics as valuable tool for near-surface urban application. The Leading Edge 3, 256-263.

Krawczyk C.M., Polom U., Trabs S. and Dahm T. 2012. Sinkholes in the city of Hamburg - New urban shear-wave reflection seismic system enables high-resolution imaging of subrosion structures. Journal of Applied Geophysics 78, 133-143.

Lane J.W., White E.A., Steele G.V. and Cannia J.C. 2008. Estimation of bedrock depth using the horizontal-to-vertical $(\mathrm{H} / \mathrm{V})$ ambient-noise seismic method. 21st EEGS symposium on the application of geophysics to engineering and environmental problems, 490-502.

Larose E., Carrière S., Voisin C., Bottelin P., Baillet L., Guéguen P et al. 2015. Environmental seismology: what can we learn on earth surface processes with ambient noise? Journal of Applied Geophysics 116, $62-74$.

Lazzari M., Loperte A. and Perrone A. 2010. Near surface geophysics techniques and geomorphological approach to reconstruct the hazard cave map in historical and urban areas. Advances in Geosciences 24, $35-44$.

Lee E.J., Shin S.Y., Ko B.C. and Chang C. 2016. Early sinkhole detection using a drone-based thermal camera image. Infrared Physics \& Technology 78, 223-232.

Lermo J. and Chavez-Garcia J. 1994. Are microtremors useful in site response evaluation? Bullettin of the Seismological Society of America 84, 1350-1364.

Loke M.H. and Barker R.D. 1996. Practical techniques for 3D resistivity surveys and data inversion. Geophysical Prospecting 44, 499-523.

Lotti A., Lazzeri A.M., Beja S. and Pazzi V. 2017. Could ambient vibration be related to Cerithidea decollata migration? International Journal of Geoscience 8, 286-295.

Lotti A., Saccorotti G., Fiaschi A., Matassoni L., Gigli G., Pazzi V. et al. 2015. Seismic monitoring of rockslide: the Torgiovannetto quarry (Central Apennines, Italy). In: Engineering Geology for Society and Territory, Vol. 2 (eds G. Lollino et al.), pp. 1537-1540. Springer International Publishing, Switzerland.

Maineri C., Benvenuti M., Costagliola P., Dini A., Lattanti P., Ruggeri G. et al. 2003. Sericitic alteration at the La Crocetta deposits (Elba Island, Italy): interplay between magmatism, tectonic and hydrothermal activity. Miner Deposita 38, 6-86.

Martì D., Carbonell R., Flecha I., Palomeras I., Font-Capó J., VázquezSuñé E. et al. 2008. High-resolution seismic characterization in an urban area: subway tunnel construction in Barcelona, Spain. Geophysics 73, B41-B50.

Martinez-Moreno F.J., Pedrera A., Ruano P., Galindo-Zaldivar J., Martos-Rosillo S., Gonzalez-Castillo L. et al. 2013. Combined microgravity, electrical resistivity tomography and induced polarization to detect deeply buried caves: Algaidilla cave (Southern Spain). Engineering Geology 162, 67-78.

McDonald R. and Davies R. 2003. Integrated geophysical surveys applied to karstic studies. First Break 21, 32-35.

Miller R. 2010. Introduction to this special section: urban geophysics. The Leading Edge 3, 248-249.

Milsom J. and Eriksen A. 2011. Field Geophysics. John Wiley and Sons, Ltd., Publication, 304pp.

Murali S. and Patangay N.S. 2006. Principles of Application of Groundwater Geophysics. Hyderabad, India: Association of Geophysicists, 419pp.

Nakamura Y. 1989. A method for dynamic characteristics estimation of subsurface using microtremor on the ground surface. Quarterly Report of the Railway Technical Research Institute 30, 25-33.

Newton J.G. and Mark Tanner J. 1987. Case histories of induced sinkholes in the eastern United States. In: Karst Hydrogeology: Engineering and Environmental Applications: Proceedings of the Second Multidisciplinary Conference on Sinkholes and the Environmental Impacts of Karsts, Orlando, Florida, February 1987, pp. 15-23. (eds B.F. Beck and W.L. Wilson), Paine J.G., Buckley S.M., Collins E.W. and Wilson C.R. 2012. Assessing collapse risk in evaporite sinkholeprone areas using microgravimetry and radar interferometry. Journal of Environmental and Engineering Geophysics 17, 75-87.

Parise M. and Lollino P. 2011. A preliminary analysis of failure mechanisms in karst and man-made underground caves in Southern Italy. Geomorphology 134(1-2), 132-143. 
Pazzi V., Lotti A., Chiara P., Lombardi L., Nocentini M. and Casagli N. 2017a. Monitoring of the vibration induced on the Arno masonry embankment wall by the conservation works after the May 25, 2016 riverbank landslide. Geoenvironmental Disasters 4(6).

Pazzi V., Morelli S., Fidolini F., Krymi E., Casagli N. and Fanti R. 2016a. Testing cost-effective methodologies for flood and seismic vulnerability assessment in communities of developing countries (Dajç northern Albania). Geomatics, Natural Hazards and Risk 7, 971-999.

Pazzi V., Morelli S., Pratesi F., Sodi T., Valori L., Gambacciani L. et al. 2016b. Assessing the safety of schools affected by geo-hydrologic hazards: the geohazard safety classification (GSC). International Journal of Disaster Risk Reduction 15, 80-93.

Pazzi V., Tanteri L., Bicocchi G., D’Ambosio M., Caselli A. and Fanti R. 2017b. H/V measurements as an effective tool for the reliable detection of landslide slip surfaces: case studies of Castagnola (La Spezia, Italy) and Roccalbegna (Grosseto, Italy). Physics and Chemistry of the Earth 98, 136-153.

Pazzi V., Tapete D., Cappuccini L. and Fanti R. 2016c. An electric and electromagnetic geophysical approach for subsurface investigation of anthropogenic mounds in an urban environment. Geomorphology 273, 335-347.

Piro S., Tsourlos P.I. and Tsokas G.N. 2001. Cavity detection employing advanced geophysical techniques: a case study. European Journal of Environmental and Engineering Geophysics 6, 3-31.

Pueyo Anchuela O., Casas-Sainz A.M., Soriano M.A. and Pocovi-Juan A. 2009. Mapping subsurface karst features with GPR: results and limitations. Environmental Geology 58, 391-399.

Pueyo Anchuela O., Pocovi Juan A., Casas-Sainz A.M., Anson-Lopez D. and Gil-Garbi H. 2013. Actual extension of sinkholes: considerations about geophysical, geomorphological, and field inspection techniques in urban palnning projects in the Ebro basin (NE Spain). Geomorphology 189, 135-149.

Reitz H.M. and Eskridge D.S. 1977. Construction methods which recognize the mechanics of sinkhole development. In: Hydrologic problems in karst regions (eds R.R. Dilamartes and S.C. Csannaly), pp. 432 438. Wester Kentucky University, Bowlking Green, Kentucky.

Reynolds J.M. 2011. An Introduction to Applied and Environmental Geophysics, 2nd edn. Oxford: Wiley.
Rocchi S., Westerman D.S., Dini A., Innocenti F. and Tonarini S. 2002. Two-stage growth of laccoliths at Elba Island, Italy. Geology 30, 938-986.

Samyn K., Mathieu F., Bitri A., Nachbaur A. and Closset L. 2014. Integrated geophysical approach in assessing karst presence and sinkhole susceptibility along flood-protection dykes of the Loire River, Orléans, France. Engineering Geology 183, 170-184.

Santarato G., Ranieri G., Occhi M., Morelli G., Fischanger F. and Gualerzi D. 2011. Three-dimensional electrical resistivity tomography to control the injection of expanding resins for the treatment and stabilization of foundation soils. Engineering Geology 119, 18-30.

SESAME 2004. Guidelines for the implementation of the H/V spectral ratio technique on ambient vibrations. Measurements, processing and interpretation. SESAME European research project, WP12Deliverable D23.12, European Commission-Research General Directorate, Project No. EVG1-CT-2000-00026 SESAME.

Sgarlato G., Lombardo G. and Rigano R. 2011. Evaluation of seismic site response nearby underground cavities using earthquake and ambient noise recordings: a case study in Catania area, Italy. Engineering Geology 122, 281-291.

Smith D.L. 1986. Application of the pole-dipole resistivity technique to the detection of solution cavities beneath highways. Geophysics 51, 833-837.

Smith D.L. and Randazzo A.F. 1975. Detection of subsurface solution cavities in Florida using electrical resistivity measurements. Southeastern Geology 16(4), 227-240.

Sogage J., Vichabian Y. and Dale Morgan F. 1999. Induced polarization in the detection of cave system. Proceedings of the Symposium on the Application of Geophysics to Engineering and Environmental Problems, pp. 317-321. Environmental and Engineering Geophysical Society.

Szalai S. and Szarka L. 2008. On the classification of surface geoelectric arrays. Geophysical Prospecting 56, 159-175.

Telford W.M., Geldart L.P. and Sheriff R.E. 1990. Applied Geophysics, 2nd edn. Cambridge, UK: Cambridge University Press.

Trevisan L. 1950. L'Elba orientale e la sua tettonica di scivolamento per gravità. Soc. Coop. Tipogr.

USGS 2016. http://water.usgs.gov/edu/sinkholes.html.

Zhou W., Beck B.F. and Adams A.L. 2002. Effective electrode array in mapping karst hazards in electrical resistivity tomography. Environmental Geology 42, 922-928. 